BMJ Open Sport \& Exercise Medicine

\title{
Assessment of fitness for recreational scuba diving in candidates with asthma: a pilot study
}

\author{
Amalie Ustrup, ${ }^{1}$ Signe Knag Pedersen, ${ }^{1}$ Charlotte Suppli Ulrik (D) ${ }^{1,2}$
}

To cite: Ustrup A, Pedersen SK, Suppli Ulrik C. Assessment of fitness for recreational scuba diving in candidates with asthma: a pilot study. BMJ Open Sport \& Exercise Medicine 2020;6:e00624. doi:10.1136/ bmjsem-2019-000624

Accepted 15 December 2019
Check for updates

(C) Author(s) (or their employer(s)) 2020. Re-use permitted under CC BY-NC. No commercial re-use. See rights and permissions. Published by BMJ.

${ }^{1}$ Respiratory Research Unit, Hvidovre Hospital, Hvidovre, Denmark

${ }^{2}$ Institute of Clinical Medicine, University of Copenhagen, Copenhagen, Denmark

\section{ABSTRACT}

Background Asthma may be regarded as a

contraindication to scuba diving.

Purpose A clinical algorithm to assess fitness to dive among individuals with asthma was developed and tested prospectively in clinical practice.

Study design Cohort study.

Methods All patients with possible asthma referred to Hvidovre Hospital, Denmark, for assessment of fitness to dive over a 5-year period (2013-2017) were included. Fitness to dive was assessed by case history, spirometry and mannitol challenge test. All patients with $\geq 10 \%$ decline in forced expiratory volume in $1 \mathrm{~s}\left(\mathrm{FEV}_{1}\right)$ (at any point during the challenge test) were offered step-up asthma therapy and rechallenge after at least 3 months. Patients with $<10 \%$ decline in $\mathrm{FEV}_{1}$ after administration of a maximum dose of mannitol at the latest challenge were classified as having no medical contraindications to scuba diving.

Results The study cohort comprised 41 patients (24 men; mean age 33 years), of whom $71 \%$ and $63 \%$ of men and women, respectively, were treated with rescue bronchodilator and inhaled corticosteroid. After the first mannitol challenge test, 21 patients were classified as having no medical contraindications to scuba diving, of whom 16 were currently prescribed asthma medication. After step-up asthma therapy and rechallenge test, an additional seven patients were classified as having no medical contraindications to scuba diving. Overall, using this clinical algorithm, $28(68 \%)$ of the referred patients were finally assessed as having no medical contraindications to scuba diving.

Conclusion Using a clinical algorithm with mannitol challenge to assess fitness to dive among patients with possible asthma and allowing a rechallenge test after stepup asthma therapy increased the proportion of individuals classified as having no medical contraindications to scuba diving. However, as this algorithm has so far not been evaluated against actual scuba diving safety, further studies are clearly needed before it can be implemented with confidence for use in clinical practice.

Clinical relevance An algorithm to assess fitness for scuba diving among individuals with possible asthma using bronchial challenge test, with the option of step-up asthma therapy and rechallenge for reassessment, has been developed for clinical use.

\section{What is known about the subject}

- The risks of diving with asthma are unknown, and it is therefore debated whether or not individuals with asthma should be excluded from diving.

\section{What this study adds to existing knowledge}

This study developed an algorithm that increased the proportion of individuals with asthma being classified as having no medical contraindications to scuba diving.

\section{INTRODUCTION}

Since the scuba device was invented in the 1940 s, it has been debated whether or not asthma should be regarded as a contraindication to diving due to multiple theoretical concerns, one of them that bronchospasm, and by that air trapping, can occur while the diver is under water. Despite several attempts, no studies have reported that diving with asthma is indeed a risk factor and therefore should be regarded as an absolute contraindication. ${ }^{1}$ At present, there is general acceptance, not least in the diving community, that probably not all individuals suffering from asthma should be excluded from recreational diving. However, there remains no consensus on how to assess fitness for recreational scuba diving in clinical practice. ${ }^{2} \mathrm{~A}$ clinical algorithm has therefore been developed (by the senior author of this study) at Hvidovre Hospital on how to assess fitness to dive in candidates with possible asthma, even though evidence is at best limited. In line with this, the objective of the present study was to test this algorithm in clinical practice.

\section{MATERIALS AND METHODS}

\section{Characteristics of enrolled patients}

All patients with asthma or possible asthma referred to Hvidovre University Hospital, Denmark, for assessment of fitness for recreational scuba diving over a 5-year period 
(2013-2017) were prospectively included in the present study.

Case history was obtained from all patients. Family disposition to asthma and allergy, that is, relatives with a diagnosis of asthma or allergies, and atopic disease and symptoms, including wheezing, dyspnoea, coughing, chest tightness, recurrent lower respiratory tract infections, exercise-induced wheezing, exercise-induced cough, night-time respiratory symptoms (coughing or wheezing during night-time) and symptoms of rhinitis, were recorded together with, if relevant, previous diagnosis of asthma and currently prescribed antiasthma therapy. Patients were categorised as smokers or never smokers, and lifetime tobacco exposure was calculated as pack-years (one pack-year=20 cigarettes a day for 1 year).

\section{Methods}

Spirometry, and if spirometry revealed signs of airflow limitation also bronchodilator reversibility test, measurement of fractional exhaled nitric oxide $\left(\mathrm{F}_{\mathrm{F}} \mathrm{NO}\right)$ and skin prick test were performed as part of the routine work-up for patients seen at the respiratory outpatient clinic for asthma.

\section{Spirometry}

Baseline spirometry included forced vital capacity (FVC) and forced expiratory volume in $1 \mathrm{~s}\left(\mathrm{FEV}_{1}\right)$ in litres and per cent predicted ${ }^{3}$ and $\mathrm{FEV}_{1}: \mathrm{FVC}$ ratio. Findings from the bronchodilator reversibility test were recorded, if available.

\section{Fractional exhaled nitric oxide}

$\mathrm{F}_{\mathrm{E}} \mathrm{NO}$ was measured in all patients prior to the mannitol challenge test. $\mathrm{F}_{\mathrm{E}} \mathrm{NO}$ levels were measured online (rate $50 \mathrm{~mL} / \mathrm{s}$ ) with the nitric oxide analyser (NIOX; Aerocrine, Solna, Sweden) and according to the American Thoracic Society guidelines ${ }^{4}$ and expressed in parts per billion (ppb). $\mathrm{F}_{\mathrm{E}} \mathrm{NO}$ was reported as the mean of two measurements.

\section{Skin prick test}

The skin prick test was done with common aeroallergens, that is, birch, grass, mugwort, horse, dogs, cats, Dermatophagoides pteronyssinus, D. farinae, Aspergillus fumigatus, Alternaria iridis and Cladosporium herbarum. Allergens were tested together with negative and positive controls, read after 15-20 min of application, with a positive result defined as a weal $\geq 3 \mathrm{~mm}$ in diameter. ${ }^{5}$

\section{Mannitol challenge test}

Bronchial provocation test with mannitol was performed in all included individuals as part of the clinical assessment algorithm. The mannitol challenge test was performed using a commercially available kit (Aridol/Osmohale) with prefilled capsules of mannitol at different doses (0-160 mg). The mannitol capsules were administered by inhalation in nine doses up to a cumulative dose of $635 \mathrm{mg}(5,10,20,40,2 \times 40,4 \times 40,4 \times 40,4 \times 40 \mathrm{mg})$. The $\mathrm{FEV}_{1}$ recorded after inhalation of a $0 \mathrm{mg}$ placebo capsule constituted the value used for calculating the target value, that is, $15 \%$ decline. A standard mannitol challenge test is positive when a $15 \%$ decline from baseline in $\mathrm{FEV}_{1}$ is observed, that is, $\mathrm{PD}_{15}$. In this study, however, a positive test, that is, being classified as having no medical contraindications to scuba diving, was defined as a $10 \%$ decline from baseline in $\mathrm{FEV}_{1}$. The test was stopped when a cumulative dose of $635 \mathrm{mg}$ was reached or if a $10 \%$ decline from baseline in $\mathrm{FEV}_{1}$ was observed, in accordance with the guidelines of the Danish Flying and Diving Society.

Patients were told not to take rescue bronchodilators (short-acting beta ${ }_{2}$ agonist, SABA) or smoke at least 6 hours before the test, and if necessary the test was rescheduled. Patients were informed to continue using all maintenance asthma therapy as prescribed; hence, the bronchial challenge test was done on currently prescribed maintenance therapy.

\section{Clinical algorithm for assessment of fitness to dive in patients with possible asthma}

According to the national guideline, individuals with $<10 \%$ decline in $\mathrm{FEV}_{1}$ following administration of the highest dose in a bronchial challenge test with, for example, methacholine or mannitol can be regarded as having no medical contraindications to scuba diving. ${ }^{6-8}$ The present clinical algorithm applied mannitol challenge test. The mannitol test is an indirect bronchial provocation test which in general is more specific for identifying individuals with current airways inflammation because it causes release of mediators from inflammatory cells in the airways. The mannitol test is one of the more indirect tests (others include hypertonic saline, dry-air hyperpnoea and exercise) and is applied to this algorithm due to ease of use in everyday clinical practice. According to the algorithm, all individuals with a decline in $\mathrm{FEV}_{1}$ $\geq 10 \%$ were offered rechallenge test with mannitol after stepping up their asthma therapy, primarily increasing the dose of inhaled corticosteroid (ICS) and/or add-on long-acting beta ${ }_{2}$ agonist (LABA), after a minimum of 3 months. After the rechallenge, individuals with a decline in $\mathrm{FEV}_{1}<10 \%$ were classified as having no medical contraindications to scuba diving.

\section{Statistical analysis}

Data were analysed using SPSS V.23. The results are expressed as mean $\pm \mathrm{SD}$, exact number, percentages and OR with $95 \%$ CI, as appropriate. Further, when comparing the means of the divers having no medical contraindications to scuba diving versus those classified as having medical contraindications to scuba diving, independent samples t-test was used. A $p$ value $<0.05$ was considered significant.

\section{RESULTS}

\section{Baseline characteristics}

A total of 41 participants were enrolled in the study (24 men), with a mean age of 33 years (range 10-69 years). Further characteristics are given in table 1. 
Table 1 General characteristics of the 41 patients with asthma or possible asthma who had a mannitol challenge test as part of their assessment of fitness for recreational scuba diving

\begin{tabular}{|c|c|}
\hline Characteristics & Total $(\mathrm{N}=41)$ \\
\hline Male* & $58(24)$ \\
\hline Age (years) & $33 \pm 14$ \\
\hline Body mass index & $24.1 \pm 3.1$ \\
\hline \multicolumn{2}{|l|}{ Smoking habits $†$} \\
\hline Smokers* & $17(7)$ \\
\hline Pack-years & $12 \pm 6(6)$ \\
\hline Never smokers* & $61(25)$ \\
\hline Prior asthma diagnosis* & $78(32)$ \\
\hline Rhinitis* & $41(17)$ \\
\hline Predisposition to asthma* & 46 (19) \\
\hline Predisposition to allergy ${ }^{\star}$ & $41(17)$ \\
\hline
\end{tabular}

The results are given in mean $\pm S D$ and number of patients.

${ }^{*}$ Percentages and number of patients.

†Includes data from 38 of 41 patients.

All patients were assessed for fitness for recreational scuba diving, of whom 28 (68\%) reported dyspnoea and $16(38 \%)$ wheezing (figure 1). Levels of lung function and $\mathrm{F}_{\mathrm{E}} \mathrm{NO}$ are given in table 2.

A total of $32(78 \%)$ participants had a doctor-diagnosed asthma prior to referral for assessment of fitness to dive. Of the 41 participants, 29 were at the time of testing prescribed SABA, including 2 patients with no diagnosis of asthma, and 26 patients (63\%) were prescribed maintenance therapy with ICS.

\section{Assessment of fitness to dive using the clinical algorithm}

First mannitol challenge test

All 41 enrolled participants who had a prior diagnosis of asthma or symptoms suggesting asthma had a mannitol challenge test. After the first mannitol challenge test, a total of 21 individuals had a decline of $<10 \%$ in $\mathrm{FEV}_{1}$ and were therefore classified as having no medical contraindications to scuba diving, according to the algorithm. Of

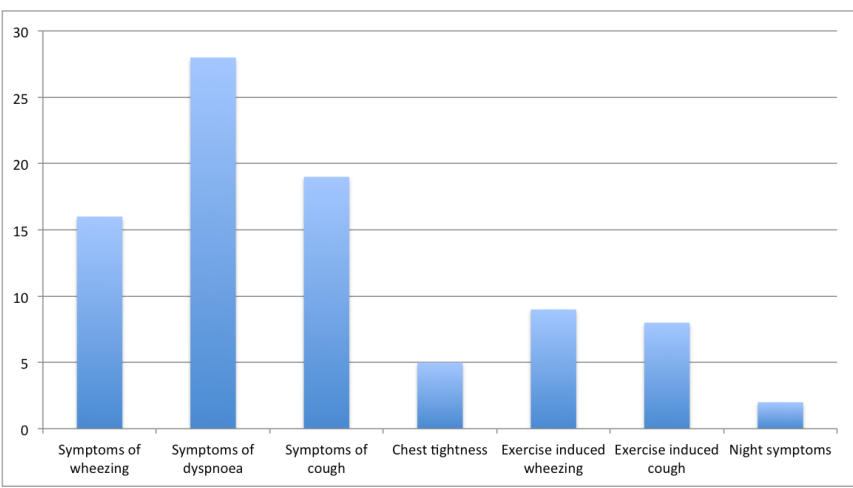

Figure 1 Symptoms of the 41 patients with asthma or possible asthma who had a mannitol challenge test as part of their assessment of fitness for recreational scuba diving.
Table 2 Spirometry and exhaled nitric oxide $\left(\mathrm{F}_{\mathrm{E}} \mathrm{NO}\right)$ in 41 individuals with asthma and/or symptoms suggesting asthma assessed for fitness for recreational scuba diving

\begin{tabular}{lll} 
& Male & Female \\
\hline FEV $_{1}$ (L) & $3.41 \pm 0.69$ & $3.26 \pm 0.46$ \\
FEV $_{1}$ (\% predicted) & $92.4 \pm 15.7$ & $98.8 \pm 12.8$ \\
FVC (L) & $4.46 \pm 0.95$ & $4.07 \pm 0.63$ \\
FVC (\% predicted) & $98.9 \pm 12.1$ & $104.4 \pm 13.4$ \\
FEV $_{1}$ :FVC & $0.78 \pm 0.08$ & $0.80 \pm 0.04$ \\
F $_{E}$ NO (ppb) & $42 \pm 31$ & $22.9 \pm 17.9$
\end{tabular}

The results are given in mean $\pm S D$.

$F_{E} N O$, fractional exhaled nitric oxide; $F_{E V}$, forced expiratory volume in $1 \mathrm{~s}$; FVC, forced vital capacity; ppb, parts per billion.

these, 15 had a prior diagnosis of asthma. All patients with a fall of $>10 \%$ in $\mathrm{FEV}_{1}$ were offered step-up asthma therapy and a rechallenge test, but six patients did not wish to continue and were therefore assessed unfit to dive. Further details are given in table 3 and figure 2.

Mannitol challenge test after step-up asthma therapy

The remaining 20 patients were offered step-up asthma therapy and rechallenge test. Six patients did not wish to continue and were therefore assessed unfit to dive. All remaining 14 patients were prescribed a higher dose of ICS and 8 patients were also prescribed add-on LABA therapy. Details of therapy adjustments before the second mannitol challenge test are given in table 4 .

At the mannitol rechallenge test, seven patients had $<10 \%$ decline in $\mathrm{FEV}_{1}$ and were therefore, according to the algorithm, classified as having no medical

Table 3 Results of initial mannitol challenge test according to current asthma therapy and outcome of the challenge test

\begin{tabular}{|c|c|c|c|}
\hline & $\begin{array}{l}<10 \% \text { fall in } \\
\text { FEV } ; \text {, no medical } \\
\text { contraindications } \\
\text { to dive }(n=21)\end{array}$ & $\begin{array}{l}>10 \% \text { fall } \\
\text { in FEV } V_{1} ; \\
\text { rechallenge } \\
\text { offered }(n=14)\end{array}$ & $\begin{array}{l}>10 \% \text { fall in } \\
\text { FEV } \mathrm{V}_{1} \text {; not } \\
\text { interested in } \\
\text { rechallenge, } \\
\text { unfit to dive } \\
(\mathrm{n}=6)\end{array}$ \\
\hline SABA & 14 & 11 & 4 \\
\hline \multicolumn{4}{|l|}{ ICS (no LABA) } \\
\hline Low (200-400) & 6 & 3 & 2 \\
\hline Medium (>400-800) & 2 & 2 & 0 \\
\hline High (>800) & 1 & 0 & 1 \\
\hline \multicolumn{4}{|l|}{ ICS (LABA add-on) } \\
\hline Low (200-400) & 1 & 2 & 2 \\
\hline Medium (>400-800) & 2 & 1 & 0 \\
\hline High $(>800)$ & 1 & 0 & 0 \\
\hline LABA (no ICS) & 1 & 0 & 0 \\
\hline LAMA & 0 & 0 & 0 \\
\hline
\end{tabular}

$\mathrm{FEV}_{1}$, forced expiratory volume in $1 \mathrm{~s}$; ICS, inhaled corticosteroid; LABA, long-acting beta agonist; LAMA, long-acting muscarinic antagonist; SABA, short-acting beta ${ }_{2}$ agonist. 


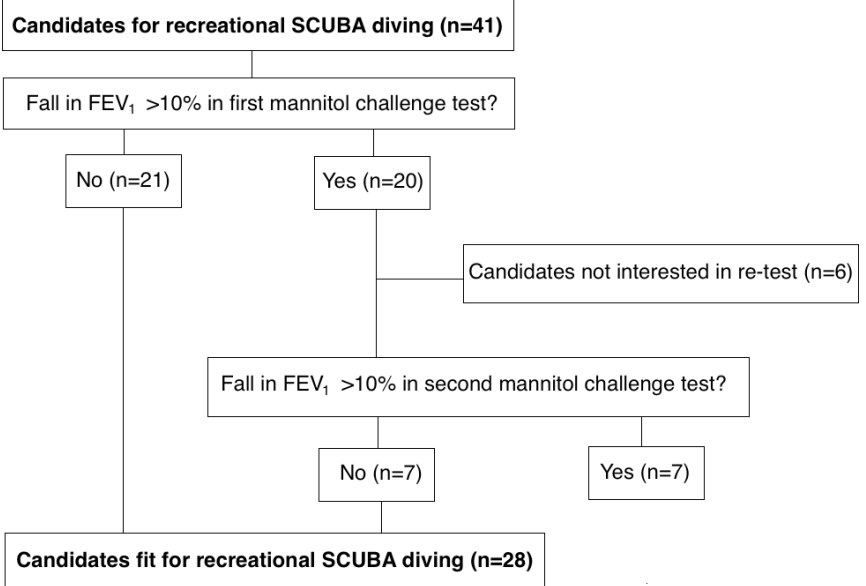

Figure 2 Flow chart showing the 41 candidates for recreational scuba diving tested with a mannitol challenge test and offered step-up asthma therapy and rechallenge test if there was a fall in $\mathrm{FEV}_{1}>10 \%$ in the first mannitol challenge test. Candidates with a fall $>10 \%$ in the retest were not fit for recreational scuba diving, along with candidates not interested in the retest. FEV 1 , forced expiratory volume in $1 \mathrm{~s}$.

contraindications to scuba diving. Five of these individuals had a prior diagnosis of asthma. The remaining seven patients had a decline of $\geq 10 \%$ in $\mathrm{FEV}_{1}$ and were therefore classified as unfit to dive (figure 2).

\section{Characteristics of individuals with no medical contraindications to scuba diving and individuals unfit to dive} Of the 41 patients, $28(68 \%)$ had no medical contraindications to scuba diving, including 20 individuals with a prior diagnosis of asthma, leaving 13 individuals (32\%) unfit to dive, including 1 patient with no prior diagnosis of asthma. This patient, however, had the highest level of $\mathrm{F}_{\mathrm{E}} \mathrm{NO}(115.5 \mathrm{ppb})$ of all participants and was afterwards diagnosed with asthma and prescribed asthma therapy. The flow of patients is shown in figure 2. When comparing individuals with no medical contraindications to scuba diving with individuals unfit to dive, no significant differences were found apart from the level of $\mathrm{F}_{\mathrm{E}} \mathrm{NO}$; that is, in patients with no medical contraindications to scuba

Table 4 Prescribed asthma therapy at the time of the mannitol rechallenge test, according to fitness to dive $(n=14)$

\begin{tabular}{lll}
\hline & $\begin{array}{l}\text { No medical } \\
\text { contraindications to } \\
\text { dive }(\mathbf{n}=\mathbf{7})\end{array}$ & $\begin{array}{l}\text { Unfit to dive } \\
(\mathbf{n}=\mathbf{7})\end{array}$ \\
\hline SABA & 5 & 6 \\
\hline ICS & & \\
\hline Low $(200-400)$ & 1 & 2 \\
Medium (>400-800) & 6 & 4 \\
\hline High $(>800)$ & 0 & 1 \\
\hline LABA add-on & 1 & 2 \\
\hline
\end{tabular}

LABA was only administered in fixed combination with ICS. ICS, inhaled corticosteroid; LABA, long-acting beta ${ }_{2}$ agonist; SABA, short-acting beta ${ }_{2}$ agonist. diving, the mean $\mathrm{F}_{\mathrm{E}} \mathrm{NO}$ was $22.8 \pm 12.4 \mathrm{ppb}$, compared with a mean of $55 \pm 36.5 \mathrm{ppb}$ in individuals classified as being unfit to dive $(\mathrm{p}=0.01)$.

\section{DISCUSSION}

The algorithm used in the present study to assess fitness for scuba diving in individuals with asthma, with the option of step-up asthma therapy and rechallenge, increased the likelihood of being classified as having no medical contraindications to scuba diving compared with assessments based on current national guidelines.

\section{Comparing national guidelines}

There are several published national guidelines around the world with different recommendations on how to assess diving candidates with asthma.

Strauss ${ }^{9}$ was the first in 1979 to suggest that contraindications to diving in subjects with asthma should include significant obstructive pulmonary disease with minimal values for $\mathrm{FEV}_{1}$ and FVC and maximum voluntary ventilation of $75 \%$ of predicted; any asthma attack occurring within the past 2 years; the need for preventive therapy; or any episode of bronchospasm associated with exertion and/or inhalation of cold air. These contraindications are based on theoretical concerns rather than evidence, and most guidelines published since then have been based on this recommendation. Today, however, most diving experts or diving societies have more liberal approaches.

The British Thoracic Society Fitness to Dive Group (a subgroup of the British Thoracic Society Standards of Care Committee) and the Danish guidelines from the Danish Society of Respiratory Medicine share content from their respective guidelines and recommend that subjects with wheezing precipitated by exercise-induced, cold-induced or emotion-induced asthma should be excluded from diving, and that subjects with asthma should refrain from diving if they have symptoms requiring relief medication in the 48 hours preceding the dive and if they have reduced fall in peak expiratory flow (PEF) $>10 \%$ from best values or increased peak flow variability $>20 \%$ diurnal variation. ${ }^{8}{ }^{10}$ Further, according to the Danish national guideline from the Flying and Diving Medical Society, individuals with $>10 \%$ decline in $\mathrm{FEV}_{1}$ following administration of the highest dose in a bronchial challenge test with, for example, methacholine or mannitol are classified as unfit for scuba diving. ${ }^{8}$

In the USA, the National Institutes of Health in 2016 published recommendations that allow subjects with wellcontrolled, mild-to-moderate asthma, that is, no current chest symptoms and with normal screening spirometry, to go scuba diving. The recommendation also states that patients with exercise-induced, emotion-induced and cold-induced asthma, along with patients with asthma requiring rescue medication within 48 hours, should not dive. Furthermore, the US recommendations point to other diving societies recommending that a patient with asthma should successfully pass a bronchial provocation challenge. $^{11}$ 
In Australia and New Zealand, the South Pacific Underwater Medicine Society (SPUMS) recommends that candidates who indicate a history of asthma in the last 10 years and exhibit signs of wheezing or an unexplained cough, but have normal spirometry, should have bronchial provocation test, using indirect methods including dry-air hyperpnoea, exercise and hypertonic challenges (saline or mannitol). A positive response, that is, a reduction in $\mathrm{FEV}_{1}$ of greater than $15 \%$, should lead to a recommendation against diving, but does not preclude retest and reassessment after asthma control has been established. Those who 'pass' bronchial provocation tests and are taking antiasthma medication should be reassessed annually or sooner if they develop any symptoms. It is further recommended that 'well-controlled' individuals with asthma, that is, asymptomatic and show normal lung function on testing with spirometry and bronchial provocation, may be able to dive at an acceptable level of risk. All current divers with controlled asthma are strongly encouraged to monitor their peak flow twice daily during diving periods, with the recommendation to refrain from diving if PEF is more than $10 \%$ below their best value. ${ }^{12}$

There is no worldwide consensus on assessment, and this is primarily due to the limited evidence. National guidelines are mainly based on expert opinions, case reports of diving accidents, epidemiological data, anonymous questionnaires, experimental studies with real or simulated dives, and annual reports of diving fatalities, injuries and incidents, ${ }^{13-17}$ and none has generated direct evidence that diving with asthma increases the risk of misadventure. Future studies should therefore address the actual risk related to recreational scuba diving in individuals with asthma and the impact on the risk of level of asthma control, and larger studies using a clinical algorithm that assesses fitness to dive are necessary.

\section{Impact of asthma triggers on fitness to dive}

Most experts seem to agree that subjects with exerciseinduced, cold-induced or emotion-induced asthma should be excluded from diving. ${ }^{2} 718-20$ The SPUMS guidelines on medical risk assessment for recreational diving do not, however, take this aspect into account. ${ }^{12}$ The present algorithm is not excluding divers with history of wheezing and/or other asthma symptoms triggered by exercise, cold or emotion, primarily due to the lack of evidence on an association between these symptoms and dive-related injuries. ${ }^{21}$ The concern is that the diving environment can be physically challenging and cold and trigger anxiety, and therefore cause an asthma attack. It is still worth noting that this concern is theoretical and that no evidence is indicating that candidates with exerciseinduced, cold-induced or emotion-induced asthma with a negative mannitol challenge test and therefore no evidence of airway hyper-responsiveness should not be as fit to dive as other patients with asthma. Since there is no gold standard on how to assess fitness for recreational scuba diving in individuals with asthma or symptoms of asthma, this algorithm was developed for use in everyday clinical practice, but is limited on safety since it is not known whether or not diving with asthma is an actual risk factor for injuries.

\section{Future investigations}

To know more about potential risks when diving with asthma, more studies are needed. Due to ethical concerns about performing randomised clinical trials in this setting, the use of real-world experience, registry data and surveys is the only means to gain insight into the risks and recommendations when diving with asthma or symptoms of asthma.

\section{Study limitations}

The study is limited on safety since there is no evidence on how asthma affects recreational scuba diving and therefore no gold standard for assessment of fitness to dive with asthma.

\section{CONCLUSION}

The present study tested a clinical algorithm developed at Hvidovre Hospital on how to assess fitness to dive in candidates with possible asthma. It showed an increase in the proportion of candidates being classified with no medical contraindications to scuba diving when mannitol challenge test is performed and allowing a rechallenge test after a step-up asthma therapy. However, it is important to note that this algorithm has not been evaluated against the actual safety of recreational scuba diving, and therefore further studies are clearly needed before it can be implemented safely for use in clinical practice.

Acknowledgements The authors wish to thank all participating patients and the nurses in the respiratory outpatients clinic at Hvidovre Hospital for doing the bronchial challenge tests.

Contributors CSU developed the clinical algorithm tested in the present study and is the guarantor of the study. ASU, SKP and CSU contributed to the acquisition of data. ASU and CSU analysed the data. ASU drafted the first version of the manuscript. All authors contributed to interpreting the data and revising the manuscript, and approved the final manuscript.

Funding The authors have not declared a specific grant for this research from any funding agency in the public, commercial or not-for-profit sectors.

Competing interests None declared.

Patient consent for publication Not required.

Ethics approval This study was approved by the ethics committee of the Capital Region of Denmark (H-D-2016-0051).

Provenance and peer review Not commissioned; externally peer reviewed.

Data availability statement Data are available upon reasonable request.

Open access This is an open access article distributed in accordance with the Creative Commons Attribution Non Commercial (CC BY-NC 4.0) license, which permits others to distribute, remix, adapt, build upon this work non-commercially, and license their derivative works on different terms, provided the original work is properly cited, appropriate credit is given, any changes made indicated, and the use is non-commercial. See: http://creativecommons.org/licenses/by-nc/4.0/.

ORCID iD

Charlotte Suppli Ulrik http://orcid.org/0000-0001-8689-3695

\section{REFERENCES}

1 Ustrup AS, Ulrik CS. Are recreational scuba divers with asthma at increased risk? J Asthma 2017;54:784-91. 
2 Adir Y, Bove AA. Can asthmatic subjects dive? Eur Respir Rev 2016;25:214-20.

3 Miller MR, Hankinson J, Brusasco V, et al. Standardisation of spirometry. Eur Respir J 2005;26:319-38.

4 Selkoff P, Hunt J. Ats workshop proceedings: exhaled nitric oxide and nitric oxide oxidative metabolism in exhaled breath condensate: Executive summary. Am J Respir Crit Care Med 2006;173:811-3.

5 Heinzerling L, Mari A, Bergmann K-C, et al. The skin prick test European standards. Clin Transl Allergy 2013;3:3.

6 Douglas G, Higgins B, Barnes N, et al. British guideline on the management of asthma. Thorax 2014;69:1-192.

7 Douglas GH, Barnes B; N; Boyter A. British guideline on the management of asthma. Thorax 2014;69:1-192.

8 Rasmussen K, Ustrup A, Jeschke K, et al. Dykning OG lungesygdom, 2017. Available: https://http://www.lungemedicin.dk/ fagligt/43-dykning-og-lungesygdom.html

9 Strauss RH. Diving medicine. Am Rev Respir Dis 1979;119:1001-23.

10 UKDMC. Medical conditions: asthma, 2019. Available: http://www. ukdmc.org/medical-conditions/asthma/

11 Coop CA, Adams KE, Webb CN. Scuba diving and asthma: clinical recommendations and safety. Clin Rev Allergy Immunol 2016;50:18-22.

12 SPUMS medical 4th edition 2011. Available: https://http://www. spums.org.au/content/spums-full-medical-0

13 Buzzacott P. Divers alert network annual diving reports. DAN annual diving report 2017 edition: a report on 2015 diving fatalities, injuries, and incidents. Durham (NC), 2017.
14 Farrell P, Glanvill P. Diving practices of scuba divers with asthma. BMJ (Clinical research ed). 1990;300:166.

15 Ivkovic D, Markovic M, Todorovic BS, et al. Effect of a single pool dive on pulmonary function in asthmatic and non-asthmatic divers. Diving Hyperb Med 2012;42:72-7.

16 Tetzlaff K, Muth CM. Demographics and respiratory illness prevalence of sport scuba divers. Int J Sports Med 2005;26:607-10.

17 Trout BM, Caruso JL, Nelson C. Divers Alert Network Annual Diving Reports. In: Buzzacott P, ed. Dan annual diving report 2012-2015 edition: a report on 2010-2013 data on diving fatalities, injuries, and incidents. Durham (NC): Divers Alert Network, 2015

18 Godden D, Currie G, Denison D, et al. British thoracic Society guidelines on respiratory aspects of fitness for diving. Thorax 2003:58:3-13.

19 Harrison D, Lloyd-Smith R, Khazei A, et al. Controversies in the medical clearance of recreational scuba divers: updates on asthma diabetes mellitus, coronary artery disease, and patent foramen ovale. Curr Sports Med Rep 2005;4:275-81.

20 Jenkins C, Anderson SD, Wong R, et al. Compressed air diving and respiratory disease. A discussion document of the thoracic Society of Australia and New Zealand. Med J Aust 1993:158:275-9.

21 Ranapurwala SI, Kucera KL, Denoble PJ. The healthy diver: a cross-sectional survey to evaluate the health status of recreational scuba diver members of divers alert network (DAN). PLoS One 2018;13:e0194380. 